\title{
Effect of ingestion of fat on ileostomy effluent
}

\author{
S E Higham, N W Read
}

\begin{abstract}
Infusion of fat into the ileum slows small bowel transit and increases absorption of a carbohydrate meal. Paired studies were undertaken to investigate the effect of adding fat to the diet on gastrointestinal transit and absorption in eight people with terminal ileostomies. Each subject ate a daily diet that contained either low or high levels of fat but equivalent amounts of carbohydrate, protein, and fibre. Solid and liquid markers were added to the food to measure transit times. The ileostomy outputs after the meals were analysed for protein, fat, carbohydrate, polyethylene glycol, and the delivery of solid markers. All subjects produced more ileal effluent while taking the high fat diet compared with the low fat diet. Fat and protein outputs were significantly higher on the high fat days, but a greater proportion of the fat was absorbed during the high fat diet compared with the low fat diet. The output of carbohydrate on the two diets was not significantly different. The incorporation of fat in the diet produced no significant differences in the transit times of the first marker, but a slight prolongation of the transit time of the second marker. Increasing the fat content of the diet did not slow small bowel transit or increase nutrient absorption. The increase in protein and water output could be explained by an increased secretion of pancreatic enzymes.
\end{abstract}

Infusion of fat into the ileum delays the passage of a meal through the stomach and small intestine, ${ }^{1}$ and the associated increase in small intestinal residence is accompanied in normal subjects by enhanced absorption of a carbohydrate meal. ${ }^{2}$ Clinical observations suggest that fat taken with a meal may also slow small bowel transit and increase nutrient absorption; small bowel transit time is prolonged in patients with coeliac disease or cystic fibrosis, who have steatorrhoea, ${ }^{3+}$ and increasing the intake of fat is an effective treatment of toddler diarrhoea. ${ }^{5}$ The question addressed by this study is, 'Does the interaction of fat with small intestinal receptors regulate small bowel transit and absorption under normal circumstances or is it a mechanism that operates only under pathophysiological

Sub-Department of Human Gastrointestinal Physiology and Nutrition, Royal Hallamshire Hospital, Sheffield S E Higham N W Read

Correspondence to: Professor N W Read, Sub-Department of Human Gub-Department of Human Gastrointestinal Physiology and Nutrition, Floor K, Royal Hallamshir Hospital, Glossop Road, Sheffield S10 2JG.

Accepted for publication 27 June 1990 conditions?'. We attempted to answer this

TABLE I Composition of diets

\begin{tabular}{lcc}
\hline & High fat & Low fat \\
\hline Carbohydrate $(\mathrm{g})$ & 88 & 84 \\
Fat $(\mathbf{g})$ & 160 & 22 \\
Protein $(\mathrm{g})$ & 54 & 55 \\
Fibre $^{\star}(\mathrm{g})$ & $9 \cdot 7$ & $9 \cdot 8$ \\
$\mathrm{kcal}^{\star}$ & 2039 & $7+5$ \\
\hline
\end{tabular}

$\star$ The fibre and calorie contents were calculated from published figures." question by investigating whether a diet rich in fat would delay transit through the stomach and small intestine and increase nutrient absorption in healthy patients, equipped with terminal ileostomies.

\section{Methods}

\section{SUB JECTS}

Studies were carried out on five women and three men, who had ileostomies constructed from the end of the small intestine, but were otherwise quite healthy. In each case no more than $10 \mathrm{~cm}$ of terminal ileum was resected. The ileostomy function was normal. Only one of the subjects was on medication (anti-epilepsy drugs) and the same quantities were taken during both studies. Seven had been treated for ulcerative colitis, one for Crohn's colitis. All had given their informed consent for the study. Daily ileostomy outputs were measured in five and were not excessive, the means over five day periods were in the range $335-702 \mathrm{~g} / 24 \mathrm{~h}$.

\section{EXPERIMENTAL PROTOCOL}

Paired studies were carried out in random order on each patient with a gap of one week between each study. After fasting from $6 \mathrm{pm}$ on the previous evening, subjects consumed a diet that contained either small ( $22 \mathrm{~g}$ ) or large amounts of fat $(160 \mathrm{~g})$, but almost identical quantities of protein, carbohydrate and fibre (Table I).

The meals devised for each study day consisted of a breakfast and a late lunch. All the food was weighed, and the lunch was precooked and then frozen before being given to the patient. The low fat breakfast, which was eaten at between 8 am and 9 am consisted of two slices of toast, two scrambled eggs, lean back bacon and a milk shake drink made with $10 \mathrm{~g}$ powdered milk shake mix, and $250 \mathrm{ml}$ fully skimmed milk. The main meal was eaten as a late lunch at $3 \mathrm{pm}$ and consisted of Shepherd's pie, made of mashed potato, minced beef, onions, and peas, and cake. The high fat breakfast was similar to the low fat breakfast but included streaky bacon instead of back bacon, $50 \mathrm{~g}$ butter on the toast and in the egg, and full cream instead of skimmed milk in the milk shake. The high fat lunch incorporated more fat in the Shepherd's pie and more butter in the cake. Drinks of coffee, tea, and water were allowed and these were made with skimmed or full cream milk as appropriate. Great care was taken to design the diets so that they contained very similar amounts of protein, carbohydrate, and fibre. The wet weights of the low and high fat diets were 1226 and $1324 \mathrm{~g}$ respectively, and the dietary composition was confirmed by analysis (Table I). No other food was eaten on the study day except that provided, and identical volumes 
of liquid were consumed on both days. No alcohol was consumed on either day.

Solid and liquid markers were added to both meals. Fifty small triangular radioopaque plastic markers, side length $3 \mathrm{~mm}$, were cooked with the breakfast eggs and acted as markers for the food and $1.25 \mathrm{~g}$ polyethylene glycol was incorporated in the breakfast milk shake as a liquid marker. Fifty cylindrical plastic markers ( $2 \mathrm{~mm}$ long) were mixed with the Shepherd's pie during preparation. These not only provided a second measure of solid transit, but also indicated the recovery of the second meal. The breakfast on the second day was marked with $200 \mathrm{mg}$ carmine red, which was taken as a capsule with the food.

The ileostomy bag was emptied just before the subject ate breakfast on the study day and the contents were discarded. Thereafter ileostomy effluent was collected hourly throughout the study day while the subject was awake and samples were transferred to weighed plastic containers and chilled immediately before being frozen to $-20^{\circ} \mathrm{C}$. The bag was emptied upon awaking the next morning and at hourly intervals thereafter until the output was stained red from the carmine taken with breakfast. Any red samples were discarded.

Individual samples of ileostomy effluent were weighed and then $x$-rayed to determine the numbers of markers present. Small aliquots were removed for the polyethylene glycol assay.? The samples were then pooled and homogenised, and $1 \mathrm{~g}$ Thimerosal (sodium ethylmercurithiosalicylate, Sigma Chemical Co Ltd), was added

TABLE II Wet and dry weights, nutrient and water contents of ileostomy evacuates

\begin{tabular}{|c|c|c|c|}
\hline & High fat & Low fat & pvalue \\
\hline $\begin{array}{l}\text { Protein }(\mathbf{g}) \\
\text { Carbohydrate }(\mathbf{g}) \\
\text { Fat }(\mathbf{g}) \\
\text { Wet weight }(\mathbf{g}) \\
\text { Dry weight }(\mathbf{g}) \\
\text { Water content }(\mathbf{g})\end{array}$ & $\begin{array}{r}11.6(1.2) \\
3.9(0.5) \\
6.8(0.8) \\
532(35) \\
60.0(3.7) \\
472(38)\end{array}$ & $\begin{array}{c}8 \cdot 8(0 \cdot 9) \\
3 \cdot 7(0 \cdot 3) \\
2 \cdot 6(0 \cdot 3) \\
397(22) \\
47 \cdot 9(2 \cdot 6) \\
349(19)\end{array}$ & $\begin{array}{l}<0.001 \\
>0.05 \\
<0.001 \\
<0.001 \\
<0.001 \\
<0.001\end{array}$ \\
\hline
\end{tabular}

Results are expressed as mean (SEM).

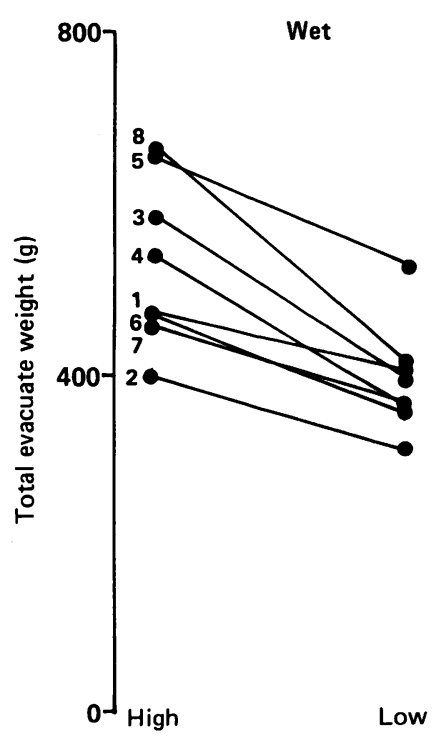

Low

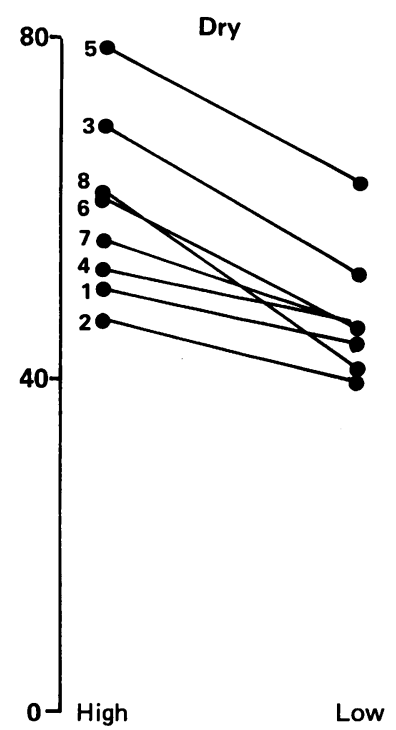

Fat level to minimise bacterial decomposition. Aliquots of $25 \mathrm{~g}$ were removed for fat analysis and the remainder was poured into shallow preweighed trays and freeze dried to constant weight (Edwards EF4 Modulyo freeze drier, attached to an Edwards high vacuum pump, model E2M5).

Carbohydrate was hydrolysed by boiling with $1 \mathrm{~mol}$ sulphuric acid and the glucose released was assayed using the GM6 glucose analyser (Analox Instruments Ltd, Brackenbury Road, Hammersmith, London). Protein was estimated by determining the total nitrogen output of the samples. The dried samples were digested with a mixture of sulphuric acid, phosphoric acid, and selenium oxide and then the nitrogen was determined spectrophotometrically using the Kjeldahl-Nesslerisation method. ${ }^{8}$ Fats were hydrolysed by refluxing with alcoholic potassium hydroxide, and the fatty acids were extracted and measured by titration against $0.1 \mathrm{mmol}$ ethanolic sodium hydroxide. ${ }^{910}$

The transit of the solid markers in the breakfast and the lunch was determined from the delivery of markers in the ileostomy effluent, and the time for delivery of $50 \%$ of markers was regarded as the time taken for half of the solid food residues to leave the small intestine. Similarly, the time at which $50 \%$ of the polyethylene glycol had appeared in the ileal effluent was regarded as the time taken for half of the liquid residues of the meal to leave the small intestine. In a previous study, we observed excellent correlations between delivery of a liquid phase marker in ileostomy effluent and delivery of fat, protein and dry matter. ${ }^{11}$

The differences between the transit times and the nutrient outputs from the two study days were assessed using a paired Student's $t$ test. Linear regression analysis was used to determine any correlation between transit times and nutrient outputs.

\section{Results}

\section{ILEOSTOMY OUTPUT}

All the patients produced more ileal effluent while taking the high fat diet compared with the low fat diet (Table II, Figs 1, 2). This was composed of significant increases in dry weight $(\mathrm{p}<0.001)$, as well as water $(\mathrm{p}<0.001)$. Although there were significant increases in the output of fat during the high fat diet, the percentage absorption of fat was much greater compared with the low fat diet $(95.8(0.50)$ and 88.1 $(1 \cdot 25) \%$ respectively; mean (SEM), $\mathrm{p}<0.001)$. The output of protein was greater on the high fat compared with the low fat diet, despite almost identical protein intakes $(\mathrm{p}<0.001)$. There was no significant difference in the output of carbohydrate from the two diets.

\section{TRANSIT MEASUREMENTS}

The transit times of the liquid and solid markers in the breakfast were unaffected by incorporating fat in the diet (Table III; Fig. 3), though the transit time of the second solid marker incorporated into the lunch was slightly longer during the high fat diet $(\mathrm{p}<0.05)$ (Fig 4). There were no 


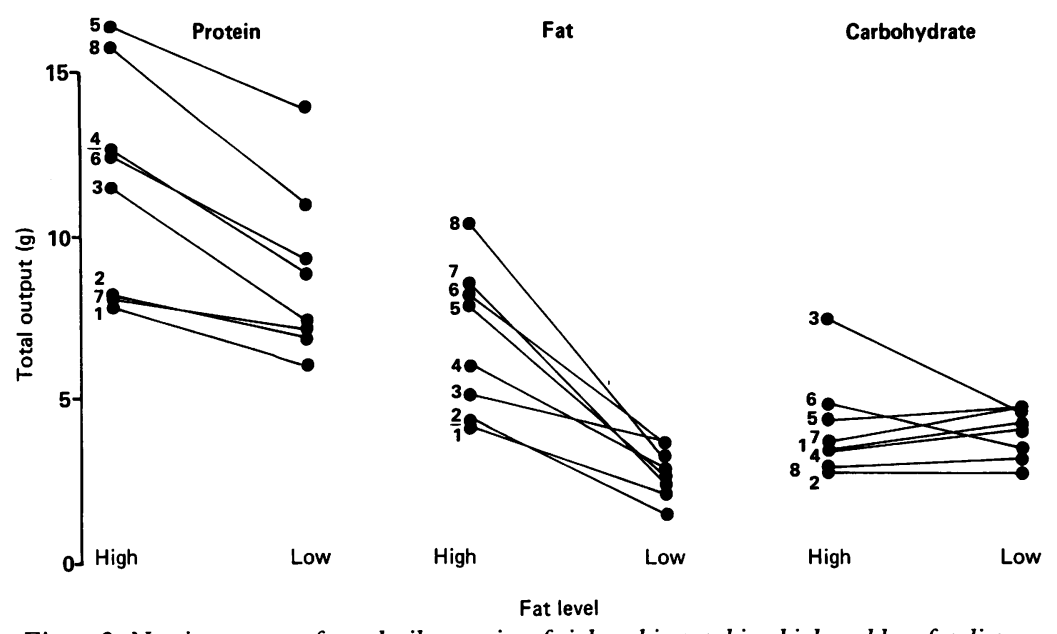

Figure 2: Nutrient outputs from the ileostomies of eight subjects taking high and low fat diets.

TABLE III Gastrointestinal transit times on low and high fat diets

\begin{tabular}{llll}
\hline & High fat & Low fat & p value \\
\hline First solid marker (h) & $15 \cdot 1(1 \cdot 8)$ & $12 \cdot 2(0.8)$ & $>0.05$ \\
Second solid marker (h) & $15 \cdot 7(1 \cdot 1)$ & $12 \cdot 3(1.7)$ & $<0.05$ \\
Polyethylene glycol (h) & $12 \cdot 2(2 \cdot 2)$ & $12.6(1.6)$ & $>0.05$ \\
\hline
\end{tabular}

Results are expressed as the mean (SEM) of the half time for delivery of each marker.

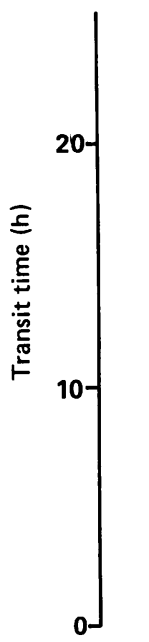

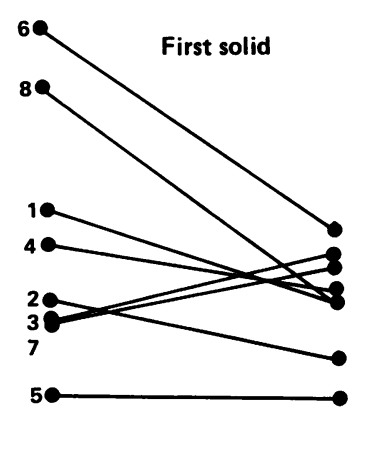

High
Low

Fat level
Figure 3: Times for delivery of $50 \%$ of the ingested solid markers to the ileostomy of eight subjects.

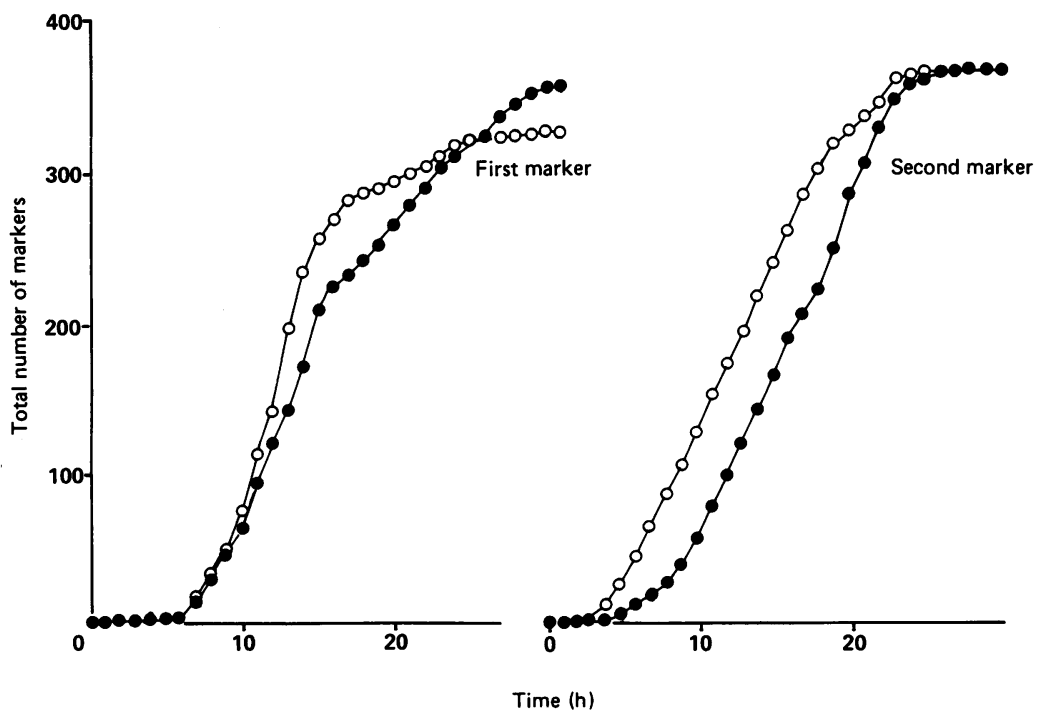

Figure 4: Pooled data from all eight subjects show the cumulative delivery of solid markers on the low fat diet $\bigcirc$, compared with the high fat diet significant differences between the transit times of the liquid and solid markers introduced into the same meal $(p<0.05)$. The recovery of the solid markers was between 92 and $100 \%$, with a median of $98 \%$.

\section{CORRELATIONS}

There were no significant correlations between transit measurements and nutrient output. The protein output was significantly correlated with the increase in wet weight for both the high $(p<0.01)$ and the low fat diets $(p<0.05)$, and the differences in protein output between the two diets were significantly correlated with the differences in wet weights $(p<0.001)$ and dry weights $(p<0.005)$

\section{Discussion}

The results of this study failed to support the hypothesis that increasing the fat content of the diet without altering the protein and carbohydrate content of the diet would slow small bowel transit and increase nutrient absorption. The transits of both solids and liquids from the two diets were very similar; only the second solid marker was significantly prolonged during ingestion of the high fat diet. In a previous study Malagelda and colleagues found that although solid markers emptied more slowly from the stomach, their small bowel transit times were very similar. ${ }^{11}$ The outputs of protein, fat, and water were actually increased on the high fat diet. The dietary manipulation would also of course increase calorie intake, but there is no evidence that calorie intake per se has any acute effect on gastrointestinal transit and absorption. The increase in fat output was relatively small $(4 \cdot 2 \mathrm{~g})$, when compared with the enormous difference in fat intake (138 g). Thus, the percentage of fat absorbed was much greater on the high fat compared with the low fat diet $(95.8 \%$ compared with $88 \cdot 1 \%)$. The increase in protein and fluid output could be explained by a greater stimulation of pancreaticobiliary secretions by the increased intake of fats. ${ }^{12} 13$

Increasing the fat content of the diet would not be expected to increase the output of carbohydrate. Instead, one might expect carbohydrate absorption to increase as a result of increased secretion of pancreatic enzymes and the expected increase in small bowel residence. Our results showed that carbohydrate output was unchanged and transit times were little affected by the high fat diet. This would perhaps indicate that the amounts of fat reaching the receptor sites, that control transit through the small intestine, are not much greater on the high fat diet than on the low fat diet. This possibility may be reflected in the small differences in the outputs of fat from the ileal stoma. Another possibility is that the increase in fluid load into the small intestine from pancreaticobiliary secretions would mask and negate any direct slowing of small bowel transit by the increased lipid diet. The latter has been evoked to explain why infusion of fat into the jejunum fails to slow small bowel transit. ${ }^{3}$

Is the ileal brake an important regulator of transit and absorption under normal physio- 
logical conditions? The answer from these studies would appear to be negative. There are two mitigating factors, however, that should be considered. First, the mechanism may be maximally stimulated by the small amounts of lipid that normally reach the ileal receptor sites even when the fat intake is very low. Second, when a high fat load is given, the ileal brake may normalise the acceleration in transit that would be expected to occur in response to increased pancreaticobiliary secretions.

Finally, an important clinical message to emerge from our data is that excessive fat intake can increase fluid and nitrogen losses in patients with ileostomies.

1 Read NW, MacFarlane A, Kinsman R, et al. Effect of infusion of nutrient solutions into the ileum on gastrointestinal transit and plasma levels of neurotensin and enteroglucagon in man. Gastroenterology 1984; 86: 274-80.

2 Holgate AM, Read NW. Effect of ileal infusion of intralipid on gastrointestinal transit, ileal flow rate and carbohydrate absorption in humans after a liquid meal. Gastroenterology 1985; 88: 1005-11.
3 Spiller RC, Trotman IF, Adriian TE, Bloom SR, Misiewicz. JJ, Silk DBA. Further characterisation of the 'ileal break' reflex in man - effects of ileal infusion of partial digests of fat protein, and starch on jejunal motility and release of neurotensin, enteroglucagon, and peptide YY. Gut 1988; 29 : 1042-51.

4 Bali A, Stapleforth DE, Asquith P. Prolonged small-intestinal transit time in cystic fibrosis. Br Med F 1983; 287: 1011-3.

5 Anonymous. Milk fat, diarrhoea, and the ileal break [Editorial]. Lancet 1986; i: 658.

6 Paul AA, Southgate DAT. The composition of foods. McCance and Widdowson, London: HMSO, 1985.

7 Malawer SJ, Powell DW. An improyed turbidimetric analysis of polyethylene glycol utilizing an emulsifier. Gastroenter$\operatorname{olog} v 1967 ; 53: 250-6$.

8 Varley H. Practical clinical biochemistry. 5th Ed. London: Heinnman, 1984: 543

9 Kamer JH van de, Huinick $\mathrm{H}$ ten B, Weijers HA. Rapid method for the Determination of fat in fecaes. 7 Biol Chem $1949 ; 177$ : $347-55$.

10 Anderson CM, French JM, Gerrard JW, Sammon SHG, Smellie JM. Coeliac disease: gastrointestinal studies and the effect of dietary wheat flour. Lancet 1952; i: 836-42.

11 Malagelada JR, Robertson JS, Brown ML, et al. Intestinal transit of solid and liquid components of a meal in health. transit of solid and liquid component

12 Malagelada J, Mimagno EP, Summerskill WHJ, Go VLN. Regulation of pancreatic gallbladder functions by intraluminal fatty acids and bile acids in man. $\mathcal{F}$ Clin Invest 1976; 58: 493-9.

13 Malagelada J, Go VLW, Summerskill WHJ. Different gastric pancreatic, and biliary responses to solid-liquid or homogenized meals. Dig Dis Sci 1979; 24: 101-10. 